\title{
Egg tarts ou pastéis de nata? A tradução da tradição em Macau
}

\author{
Raquel Abi-Sâmara ${ }^{1}$
}

Resumo: O presente ensaio consiste em uma reflexão sobre os tradicionais pastéis de nata de Macau e do Sudeste asiático, largamente conhecidos como Portuguese egg tarts. Os célebres egg tarts oferecem-se como exemplos palpáveis, doces e concretos para uma reflexão sobre a história e a tradução da cultura portuguesa na Ásia.

Palavras-chave: pastéis de nata; pastéis de Belém; Portuguese egg tarts; tradução da tradição; turismo cultural.

A primeira vez que ouvi falar dos tradicionais egg tarts de Macau foi em Cingapura, em conversa com amigos cingapureanos de origem chinesa. Logo que souberam que eu iria conhecer Macau, em 2011, recomendaram-me: "you must try the Portuguese egg tarts there, that's the most traditional and original thing in Macau, they are really the best egg tarts in Asia, and as you know they are considered one of the most traditional Portuguese desserts. When we travel to Macau, we always bring egg tarts as souvenirs to our friends". Foi assim que soube que os egg tarts são bastante apreciados em Cingapura e também em outros países do sudeste asiático, desde o final dos anos 1990, quando empresas de fast food passaram a incluí-los entre suas sobremesas. A rede KFC (Kentucky Fried Chicken), por exemplo, é um dos principais pontos de venda de egg tarts em Cingapura. E foi assim também que percebi que, o que há de mais "português" em Macau, para grande parte dos turistas do sudeste asiático, são os célebres egg tarts.

Nesses relatos turísticos, digamos, interessou-me o fato de que a mais típica sobremesa portuguesa que se pode apreciar em Macau é conhecida em sua versão inglesa: egg tart. Por que não "pastel de nata"? Turistas que visitam o Brasil, por exemplo, quase sempre voltam sabendo ao menos o significado de duas palavras básicas: "feijoada" e "caipirinha", mesmo que pronunciadas com dificuldade. E, dependendo do turista, se for alemão, por exemplo, será capaz de passar uma noite inteira discutindo cientificamente com um brasileiro que a técnica correta de preparo da caipirinha prevê a colocação do gelo antes do açúcar, e não o contrário, e daí uma série de fundamentações de natureza química. E, ainda com relação ao Brasil, se o pacote turístico incluir uma ida a Minas Gerais, o turista voltará com pelo menos mais dois ou três vocábulos gastronômicos: "pão de queijo", "queijo Minas", "cachaça". Um turista que vá a Cingapura, por sua vez, e se interesse pela comida local, voltará relatando a

1 Professora Auxiliar do Departamento de Português da Universidade de Macau, na área da tradução. Email: elmag@umac.mo 
experiência árdua (ou divertida) de ter comido um "crab", que exige destreza manual para a difícil extração da carne branca no interior das patas e carapaças resistentes. E, logo à saída do restaurante, após ter apreciado o famoso "crab", o turista lavará as mãos com um líquido misturado com limão, a fim de eliminar qualquer resquício de cheiro daquela espécie comestível de crustáceo decápode. Não é de se estranhar, no entanto, que esse mesmo turista volte contando que apreciara um "crab", já que o inglês é um dos quatro idiomas oficiais de Cingapura.

Mas, no caso de Macau, em que os idiomas oficiais são o mandarim e o português, por que será que o "pastel de nata" é vendido e amplamente conhecido como "egg tart"? Já que a sobremesa não é divulgada, entre os turistas, com seu nome original em português, ou seja, como "pastel de nata", por que então não é propagada com seu nome chinês? Em chinês, tornaram-se conhecidos como 蛋挞, que em pinyin pode ser lido como dàntà (o som parece similar à palavra portuguesa “nata”), sendo que (蛋) significa “ovo”, e (扰) significa "tarte" ou "pastel". Em cantonês, é também conhecido como pou-tat.

Os célebres "Portuguese egg tarts" oferecem-se como exemplos palpáveis, doces e concretos para uma reflexão sobre a história da cultura portuguesa na Ásia, e também sobre relações interculturais entre povos de língua portuguesa e de língua chinesa que habitam ou que circulam turisticamente por Macau. Os pastéis de nata e sua tradução não deixam de revelar construções, (des)construções e (re)construções de "identidades" culturais, ainda que de modo artificioso, promovido pela indústria turística. São exemplares de tradução, exemplares linguísticos com variantes de texturas, cores e sabores, que revelam diálogos e lacunas culturais que vêm acontecendo há cerca de cinco séculos, ou, se preferirmos, há cerca de algumas décadas em Macau.

\section{O "pastel de nata" e suas origens}

O que é "pastel de nata"? Uma consulta ao Dicionário Priberam da Língua Portuguesa online dirá: "bolo feito com massa folhada preenchida com recheio de natas". Para um falante de português do Brasil que nunca tivesse visto um pastel de nata, a explicação do Priberam o induziria a imaginar algo muito diferente do "pastel de nata", uma vez que "bolo" (ou, se quisermos um correspondente em inglês: cake) em geral apresenta-se para ele em três tamanhos relativamente padronizados (pequeno, médio e grande), sendo que o menor bolo teria algo como 10 centímetros de diâmetro, ou seja, muito maior do que um tradicional "pastel de nata". Outra dificuldade para esse mesmo falante (e leitor do Priberam online) seria o termo "natas", que evoca a cor branca do creme do leite. Mas o creme do pastel de nata, como se sabe, é 
amarelo, e inclui ovos em sua receita. O termo "pastel", no Brasil, está associado a massas salgadas e finas, fritas com recheios também salgados, como por exemplo carne moída com batatas ou simplesmente queijo. A forma do pastel geralmente é quadrada (cerca de $8 \mathrm{~cm}$ x $8 \mathrm{~cm}$ ), e, como ele estufa ao ser frito, é também conhecido como "pastel de vento". (Vale lembrar que as inúmeras pastelarias chinesas espalhadas pelos Estados do Rio de Janeiro e de São Paulo, no Brasil, vendem esse tipo de pastel).

Os "pastéis de nata", ou, mais precisamente, os egg tarts, vendidos como tradicional sobremesa portuguesa em Macau, Hong Kong e outros países da Ásia não coincidem, no entanto, com a verdadeira tradição portuguesa. Os pastéis de nata, conforme explicam os portugueses residentes em Macau, são uma variação dos “pastéis de Belém”, que começaram a ser vendidos no início do século XIX, em Belém, Portugal, no suntuoso Mosteiro dos Jerônimos. Segundo o histórico apresentado no website da pastelaria Pastéis de Belém ${ }^{2}$, esses pastéis começaram a ser vendidos numa pequena loja junto ao mosteiro, onde funcionava uma refinaria de cana-de-açúcar. Explicase que essa venda era uma tentativa de sobrevivência, logo após o encerramento de todos os conventos de Portugal, em 1834, e expulsão do clero e dos trabalhadores, em função da revolução liberal. Apesar de a área de Belém ficar distante da cidade de Lisboa, "a imponência do Mosteiro dos Jerônimos e da Torre de Belém atraíam os visitantes que depressa se habituavam a saborear os deliciosos pastéis originários do Mosteiro"3. O sucesso de venda justificou a abertura da pastelaria "Pastéis de Belém" em 1837. O nome "pastéis de Belém", assim como a receita original foram patenteados, portanto, os verdadeiros e tradicionais pastéis de Belém são única e exclusivamente aqueles fabricados, ainda hoje, por essa pastelaria, que funciona há 175 anos, e produz atualmente cerca de 15 mil pastéis por dia, o que permite a ela distribuir a iguaria para cidades portuguesas. Os pastéis similares aos pastéis de Belém passaram então a ser nomeados de "pastéis de nata”. Ou seriam os pastéis de Belém uma variante dos pastéis de nata? Em outras palavras, quem veio primeiro: os pastéis de Belém ou os pastéis de nata?

No início do século XVI, como se sabe, os portugueses chegaram a Macau, via Malaca, e ali criaram não somente um importante entreposto comercial, entre China, Japão e Europa, como também contribuíram, por permanecerem na região, para a formação de um ambiente cultural bastante peculiar, em que as culturas portuguesa e chinesa convivem, há quase cinco séculos, em relação amistosa, mas sem grandes aproximações ou enormes afinidades, como parece à primeira vista. Para aqueles que chegam em Ou Mun (topônimo original de Macau, ainda usado em chinês, que significa "portão de

2 Fonte: <http://www.pasteisdebelem.pt $>$.

3 Fonte: <http://www.pasteisdebelem.pt $>$.

fragmentum, N. 35, parte II. Laboratório Corpus: UFSM, Out./ Dez. 2012 
entrada" ou "portão da baía") cerca de 500 anos depois da chegada dos primeiros comerciantes portugueses, isto é, no ano de 2012, são evidentes as marcas desse diálogo por vezes relutante mas admiravelmente durável. Em termos genéricos, essas marcas estão nas ruas, no comércio e nos serviços em Macau. Além da arquitetura colonial portuguesa, que felizmente resiste como patrimônio histórico mundial ${ }^{4} \mathrm{em}$ meio a novas edificações e tradicionais construções chinesas, vê-se, no centro de Macau, na Praça do Leal Senado Português, o pavimento de pedras portuguesas lustradas, lindas e polidas por solados de gerações e gerações de calçados, e por um contingente significativo de mais de 78 mil turistas que circulam diariamente em Macau. ${ }^{5}$ As placas de indicação das ruas, tanto em Macau quanto em Taipa e Coloane (ilhas que pertencem a Macau), em azulejo português branco e azul cobalto, ou, muitas vezes, fundidas em ferro, apresentam os nomes de ruas escritos em português (Ruínas de São Paulo, Caminho da Horta, Beco da Alegria, Largo de Camões etc) e, simultaneamente, em caracteres chineses. No entanto, hoje, ao se tomar um táxi em Macau, raramente se vai a algum lugar quando se diz ao motorista o nome da rua, a que se quer chegar, em português. Quase sempre é preciso mostrar o nome da rua por escrito, claro, em caracteres chineses.

\section{Turismo do jogo e egg tarts versus pastéis de Belém e turismo cultural}

Embora óbvio, não podemos deixar de mencionar que o que atrai a maioria dos turistas a Macau não são naturalmente os pastéis de nata em sua versão internacional made in China, ou seja, os Portuguese egg tarts, mas sim seus megacassinos, que trouxeram a Macau o recorde de 28 milhões de turistas em 20116. Grande parte desses turistas aproveita para apreciar as culinárias cantonesa e portuguesa de Macau. Os doces cantoneses são bastante populares na China, assim como os Portuguese egg tarts, que são vendidos em todas as docerias cantonesas da Taipa Velha, vila colonial e histórica de Macau, e um dos pontos turísticos mais atrativos da região. Mas obviamente não se pode falar dos egg tarts de Macau sem se mencionar a padaria Lord Stow's, aberta em 1989 na ilha de Coloane por um inglês chamado Andrew Stow. Foi a primeira e muito bem sucedida iniciativa de produção em larga escala dos famosos pastéis, adaptados naturalmente ao paladar chinês. $O$ sucesso foi grande não somente em Macau, como em Hong Kong e em grande parte do Sudeste

\footnotetext{
${ }^{4}$ Em 2005, o "Centro Histórico de Macau” foi designado oficialmente pelo Comitê do Patrimônio Mundial da UNESCO como Patrimônio Mundial.

${ }^{5}$ No mês de julho de 2012, conforme informação do Statistics and Census Bureau (DSCE) divulgada pelo jornal Macau News de 23/08/2012, a média diária de chegada de visitantes a Macau chegou a 78.853. Se considerarmos que a população de Macau chega a 568.700 habitantes (cf. Macau News, 13/08/2012), o número de turistas diários equivale a quase $14 \%$ dessa população.

${ }^{6}$ Cf. Macau News, 11/09/2012.
}

68 fragmentum, N. 35, parte II. Laboratório Corpus: UFSM, Out./ Dez. 2012 
asiático. Pelo que se conta, a receita dos egg tarts foi vendida para a rede KFC por Margareth Wong, proprietária da loja de pastéis chamada Margaret's Café \& Nata, aberta junto com o ex-marido, Andrew Stow, no centro de Macau. ${ }^{7}$

É curioso que nos mais tradicionais pontos de venda de egg tarts em Macau, na Lord Stow's Bakery, em Coloane, assim como nas docerias cantonesas da Taipa Velha, não se conheçam necessariamente, ou mesmo nunca se tenha ouvido falar dos "pastéis de nata" portugueses. Um simples passeio pelas docerias da Rua do Cunha (Koi Kei, Choi Heong Yuen Bakery etc) prova que funcionários, e mesmo gerentes das lojas, não fazem ideia do que possa ser um "pastel de nata". No entanto, todas essas docerias expõem, logo na entrada dos estabelecimentos, em destaque, uma vitrine com os original Portuguese egg tarts, um dos produtos por elas mais vendidos, ao lado dos também famosos bolos e biscoitos de amêndoa cantoneses.

Se nesse ambiente turístico os pastéis de nata não circulam com seu nome original, em português, e se também não foram popularizados com um nome correspondente em chinês, isso prova, de alguma maneira, não só o vigor da indústria turística, que tem o inglês com língua 'oficial', como aponta também para uma vertente que mereceria ser melhor explorada no turismo de Macau. Refiro-me à vertente histórico-cultural e sua associação com a gastronomia portuguesa. Não foi por acaso que os egg tarts fizeram sucesso em Macau e na Ásia. Eles contam, ainda que de modo indireto (na 'tradução culinária' do britânico Andrew Stow) e não explícito, a influência portuguesa na Ásia. Esse é um fenômeno bastante curioso e rico: apenas num ambiente multicultural, como esse de Macau, uma tradição (no caso, a tradição dos pastéis de Belém) passa a ser mantida em sua tradução e adaptação (no caso, os "originais" Portuguese egg tarts), através de uma terceira cultura, que não é nem portuguesa e nem chinesa.

Seria interessante, no entanto, em termos interculturais, se essa doce tradução da tradição do doce português, ou seja, se esses original Portuguese egg tarts de Macau pudessem evocar ainda mais o diálogo (histórico e gastronômico) com os originais pastéis de Belém, doces-fonte que supostamente nasceram no mosteiro dos Jerônimos, em Portugal. Os célebres pastéis de Macau, do Sudeste da Ásia e de Portugal oferecem-se como saborosa fonte de inspiração para se repensar o binômio turismo e política cultural na região administrativa de Macau. Afinal, há tantas camadas de história como de massa folhada em cada egg tart ou em cada pastel de Belém que se aprecie. Não seria demasiado conhecer, através de um egg tart, a beleza suntuosa do Mosteiro dos Jerônimos ou da Torre de Belém, localizados junto à origem dos primeiros pastéis portugueses. Não seria demasiado saber que um dos papéis dos monges Jerônimos, ordem religiosa escolhida por Dom Manuel I para ocupar

7 Ver em: Macau (2012, p. 21).

fragmentum, N. 35, parte II. Laboratório Corpus: UFSM, Out./ Dez. 2012 
o Mosteiro dos Jerônimos, conforme se conta, era o de prover proteção espiritual para os navegadores e marinheiros portugueses que partiam da praia de Restelo para descobrir o mundo. ${ }^{8}$ E, para a mais perfeita tradução intercultural dos pastéis de Belém na Ásia, também não seria demasiado lembrar que o santo que inspira a ordem dos Jerônimos, ou seja, São Jerônimo (347-420), que se dedicou à tradução da Bíblia do grego antigo e do hebraico para o latim, é tido, por sua vez, como o "padroeiro dos tradutores". E, last but not least, não seria demasiado imaginar que os turistas, que em sua maioria vêm da China continental e de Hong Kong para visitar $\mathrm{Macau}^{9}$, pudessem voltar para casa sabendo pronunciar ao menos três ou quatro expressões ou palavras básicas em português: "pastel de Belém", "pastel de nata", "bacalhau" (em vez de codfish), "vinho do Porto"...

\section{Referências}

Macau, revista trimestral, IV série, n.28, setembro de 2012, p.21.

Macau News, 13.ago.2012.

Macau News, 11.set.2012.

<http://www.pasteisdebelem.pt>. Acesso em: 31.ago.2012.

${ }^{8}$ Cf. Wikipédia, “Jeronimos Monastery” (consulta feita em 10 de setembro de 2012)

${ }^{9}$ Conforme estatística do Statistics and Census Bureau (DSCE), da média diária de 78.853 turistas que chegaram em Macau no mês de julho de 2012, 59,6\% vieram da China continental, e 26,1\% chegaram de Hong Kong. (Cf. Macau News, 23/08/2012)

70 fragmentum, N. 35, parte II. Laboratório Corpus: UFSM, Out./ Dez. 2012 